\title{
Damp housing and childhood asthma; respiratory effects of indoor air temperature and relative humidity
}

\author{
D P STRACHAN ${ }^{1}$ AND C H SANDERS \\ From ' the Department of Community Medicine, University of Edinburgh; and ${ }^{2}$ the Building Research \\ Establishment, Scottish Laboratory, East Kilbride.
}

ABSTRACT In a questionnaire survey of a random sample of 1000 children aged 7 years, a significantly greater proportion of those living in homes reported as damp were affected by wheeze $(22 \% v 11 \%)$, day cough, night cough, and chesty colds. Simultaneous estimation of relative humidity in the bedrooms of 778 children and continuous 7 day recordings of ambient temperature and humidity in a stratified sample of 317 bedrooms showed no association with the same respiratory symptoms. No correlation was found between bedroom conditions and baseline ventilatory function or excercise induced reduction in $\mathrm{FEV}_{1}$. These results run counter to the widely held belief that indoor temperature and humidity are important determinants of respiratory ill health, although they do not directly exclude effects due to mites or moulds, whose survival is determined by the humidity of their respective microenvironments.

Problems of condensation and dampness in the home are a common cause of complaint ${ }^{1}$ and recent surveys in Scotland ${ }^{2}$ and England ${ }^{3}$ estimate that between one quarter and one third of homes may be affected to some degree. There is widespread public concern that housing is a cause of respiratory ill health, ${ }^{4}$ and in some areas dampness is perceived as the public health issue most in need of investigation. ${ }^{5}$ Although many symptoms might be related to cold, damp conditions, biologically plausible mechanisms are most readily invoked for those related to asthma. Cold air may be a direct trigger of attacks of bronchospasm and the survival of both house dust mites ${ }^{6}$ and fungal moulds ${ }^{7}$ depends upon high levels of ambient humidity in their respective microenvironments. On the other hand, viral respiratory infections may be more important than aeroallergens as precipitating causes of asthmatic symptoms in children, even among atopic subjects. ${ }^{89}$ Raised ambient humidity may promote the survival of viruses in droplet spray, ${ }^{1011}$ although the seasonal pattern of such infections has been interpreted as demonstrating more efficient transmission in conditions of low relative humidity. ${ }^{12}$

Epidemiological associations between damp housing and respiratory symptoms have been reported in both adults ${ }^{13}$ and children. ${ }^{514} 15$ No association with damp housing was found when general practitioner records were used in place of parental reports of symptoms in children, raising the possibility of reporting bias. ${ }^{15}$ However, in areas of local authority housing, associations have been demonstrated between respiratory symptoms in children and independent assessments of dampness ${ }^{5}$ or ambient humidity ${ }^{14}$ in the home.

The aim of our study was to investigate this relationship in a general population sample and to obtain, as far as possible, objective indicators of both disease and exposure. Seven year old children were chosen because they were old enough to cooperate with tests of ventilatory function, yet sufficiently young for active smoking to be unlikely. Furthermore, respiratory symptoms attributable to asthma are highly prevalent at this age. ${ }^{16}$

\section{Methods}

A random sample of one in three primary schools within the Edinburgh city boundary was chosen. The parents of all children in their third primary school year (age $6 \frac{1}{2}$ to $7 \frac{1}{2}$ years) were contacted in a postal questionnaire survey in November 1986. This enquired about respiratory symptoms experienced by the child in the past year, and about conditions in the home, with particular reference to heating and ventilation in the child's bedroom, condensation on windows, condensation or damp patches on walls, and visible mould growth. Consent was requested for further studies in the home, and for medical tests on 
the child at school. The study received ethical approval from the Lothian Health Board and Lothian Regional Council Education Department.

The clinical tests were performed at school over the period January to June 1987 and included measurements of ventilatory function by pneumotachograph (Vitalograph "Compact", Vitalograph Ltd, Buckingham, UK), supervised by one observer (DPS) according to the American Thoracic Society protocol. ${ }^{17}$ Spirometry was performed in the standing position, without noseclips. Measurements were taken before, and 5 and $10 \mathrm{~min}$ after a period of $6 \mathrm{~min}$ free running in corridor or classroom, taking the best of three recordings on each occasion, according to the criteria of the American Thoracic Society. ${ }^{17}$ All measurements were corrected to body temperature and pressure saturated (BTPS). Baseline spirometry was adjusted for standing height by using in the analysis the deviation of each subject's reading from the regression line of the relevant spirometric index against height among all children tested.

The reduction in forced expiratory volume in one second $\left(F V_{1}\right)$ which occurred after excercise was expressed in terms of a lability index. This was calculated as the minimum of the two post excercise $\mathrm{FEV}_{1}$ measurements divided by the $\mathrm{FEV}_{1}$ obtained before exercise. ${ }^{18}$ Data on within-subject variability of $\mathrm{FEV}_{1}$ in the same population suggested that a lability index less than 0.8 would be obtained by chance alone in only one child in one thousand. Such a value therefore indicates genuine exercise induced bronchospasm. For those asthmatic children receiving only $B_{2}$-agonist or cromoglycate inhalers, tests were performed at least $6 \mathrm{~h}$ after the last dose of bronchodilator treatment. The results from 11 children taking inhaled steroids or oral therapy for asthma were treated separately.

In mid January, participating families received a $3^{\prime \prime} \times 1^{\prime \prime} \times 1^{\text {" }}$ block of ramin hardwood, with instructions to place the block in the child's bedroom for $7 \mathrm{~d}$ and then return it in a sealed plastic bag to a collection box in the classroom. The moisture content of each block was determined within $48 \mathrm{~h}$ of collection by an electrical conductance meter (Protimeter “Diagnostic Mark III", Protimeter plc, Marlow, UK). The blocks were then allowed to equilibrate together at $55 \%$ relative humidity for $10 \mathrm{~d}$, and their moisture content was reassessed. The difference between the two moisture content readings was used as a semiquantitative estimate of the relative humidity of each child's bedroom during the week of the survey. Subsequent validation of this method, by placing a similar block beside each thermohygrograph in the field studies described below, suggested that an estimate of mean weekly relative humidity derived from the wood block survey would have a coefficient of variation of approximately $10 \%$ in the range $50 \%$ to $70 \%$ relative humidity.

All homes in the top quintile of humidity, as estimated by the wood block survey, and a sample of the remainder, comprising all the participants in eight of the larger schools, formed the target sample for more detailed measurements of temperature and relative humidity in the child's bedroom. Continuous $7 \mathrm{~d}$ recordings were charted on slowly moving drum thermohygrographs (Casella Ltd, London), which monitor temperature by bimetallic strip and relative humidity by changes in the length of a specially treated human hair. Each instrument was placed away from direct sunlight and heating appliances, and was calibrated in situ at the end of the week's recording by wet and dry bulb thermometer readings from an aspirated psychrometer. Thermohygrograph charts were digitised for computer analysis and hourly, daily and weekly mean values for temperature and relative humidity were calculated. Vapour pressure, a measure of the actual water content of the air, was derived from temperature and relative humidity using standard formulas. ${ }^{19}$

The home monitoring took place during the period January to April 1987, when mean weekly outdoor temperature ranged from -3 to $+13^{\circ} \mathrm{C}$, and mean weekly outdoor vapour pressure from 4 to $11 \mathrm{mb}$. It was therefore necessary to consider how each recording could be adjusted for climatic variations. At the start of the fieldwork, five "core" homes were chosen, which represented the range of bedroom relative humidity expected in the sample. The child's bedroom in each of these five homes was monitored continuously for the 4 months of the survey, and the indoor recordings were related to daily means for outdoor temperature and relative humidity, as recorded by the Metereological Office at Turnhouse Airport on the western outskirts of the city. The response of bedroom conditions in the "core" homes to climatic variations over the period of the study was used to derive an adjustment procedure for the temperature and relative humidity recordings in the remaining homes.

Relative humidity is a function of both vapour pressure (which reflects absolute humidity) and temperature (which determines the saturation vapour pressure at which condensation will occur). The relationship between indoor relative humidity and outdoor conditions is complex, depending upon the respective temperatures and vapour pressures. Thus in well heated bedrooms relative humidity was lower in colder weather, reflecting the lower outdoor vapour pressure usually found during the winter. However, in poorly heated bedrooms the relative humidity was higher during the winter, because it was determined by 
the indoor temperature which varied to a greater extent with external conditions.

Using daily means from each "core" home, the relationship between indoor and outdoor vapour pressure was close to linear, with a regression coefficient in each home of approximately 0.6 , so this coefficient was used in the adjustment procedure. The relationship between daily means for indoor and outdoor temperature for the same homes was more complex. The warmest bedroom was maintained at approximately constant temperature, regardless of weather conditions. On the other hand, the temperature of the coldest bedroom (which was unheated) was highly sensitive to external temperature. The remaining three bedrooms showed intermediate patterns, depending upon the efficiency of the heating and the temperature threshold at which it was used. The regression lines for indoor upon outdoor temperature in each "core" home were therefore of different slope, but tended to converge at the point corresponding to indoor temperature $22^{\circ} \mathrm{C}$, outdoor temperature $20^{\circ} \mathrm{C}$. The adjustment procedure adopted was therefore:

$$
\begin{aligned}
& \mathrm{VP}_{\mathrm{A}}=\mathrm{VP}_{\mathrm{I}}+0.6\left(9-\mathrm{VP}_{\mathrm{O}}\right) \\
& \mathrm{T}_{\mathrm{A}}=\mathrm{T}_{\mathrm{I}}+\frac{\left(22-\mathrm{T}_{\mathrm{I}}\right)\left(10-\mathrm{T}_{\mathrm{O}}\right)}{\left(20-\mathrm{T}_{\mathrm{O}}\right)}
\end{aligned}
$$

Subscripts $\mathrm{A}$, I and $\mathrm{O}$ denote adjusted indoor, measured indoor, and the concurrent outdoor recordings, respectively. Adjusted relative humidity was derived from the adjusted values for vapour pressure and temperature, using standard formulae. ${ }^{19}$ The constants in the adjustment procedure were chosen to standardise all measurements to outdoor conditions of $10^{\circ} \mathrm{C}$ and $9 \mathrm{mb}$, which are close to the annual mean temperature and vapour pressure at Turnhouse Airport.

An ideal adjustment procedure would yield adjusted indoor conditions which remained constant for each home, regardless of climatic variation. Following the adjustment procedure adopted, there remained a weak correlation with outdoor conditions, which is unlikely to influence the results substantially. For the five "core" homes, the correlation between weekly means for adjusted indoor temperature and outdoor temperature was $+0 \cdot 27$, between adjusted indoor relative humidity and outdoor temperature -0.22 , and between adjusted relative humidity and outdoor vapour pressure $-0 \cdot 15$. Pooled estimates of the within homes variability of adjusted weekly means for temperature, vapour pressure and relative humidity, expressed as a coefficient of variation, were $4.2 \%$, $7.6 \%$ and $6.0 \%$ respectively.

Statistical analysis of the thermohygrograph data was performed using SPSS-X. ${ }^{20}$ The GLIM statistical package $^{21}$ was used for logistic regression analyses of symptoms against adjusted temperature and relative humidity.

\section{Results}

The parents of 1095 children received a questionnaire, and usable replies relating to respiratory symptoms and dampness and mould in the home were obtained from $1000(91 \%)$. Consent to further participation was obtained for 941 children $(86 \%$ of the original sample), and of these, $778(83 \%)$ satisfactorily returned a ramin block. The prevalence of symptoms and housing characteristics were found to be similar among those who did and did not complete this stage of the survey.

During the week of the wood block survey, mean outdoor temperature was $+1^{\circ} \mathrm{C}$ and mean vapour pressure $5.6 \mathrm{mb}$. Snowy conditions resulted in the closure of a few schools, contributing to the incomplete response at this stage, but, advantageously, the cold weather probably accentuated differences between well heated and poorly heated bedrooms in respect of ambient relative humidity. Moisture content varied from less than $9 \%$ (the limit of detection of the instrument) to $20 \%$, equivalent to a range of relative humidity from less than $45 \%$ to over $80 \%$. The distribution was skewed to the right, with a long upper tail, mainly from rented housing. The upper quintile of moisture content consisted of values above $13 \%$ (equivalent to approximately $65 \%$ mean relative humidity).

During the subsequent 4 months, an attempt was made to visit the bedrooms of 377 children. Measurements were taken in 330 homes, and usable recordings of both temperature and relative humidity were obtained for $317(84 \%)$ of the subsample. These comprised 156 owner occupied and 161 rented homes, and included 131 bedrooms from the top quintile of the distribution of estimated relative humidity. Mean weekly temperatures as recorded ranged from 5.8 to $22.9^{\circ} \mathrm{C}$; after adjustment the distribution was approximately normal with mean $17.8^{\circ} \mathrm{C}$ and standard deviation $1.8^{\circ} \mathrm{C}$. Mean weekly relative humidity as recorded ranged from $28 \%$ to $77 \%$; after adjustment the distribution was approximately normal with mean $53 \%$ and standard deviation $6.5 \%$.

The relationships between the adjusted weekly means for temperature and relative humidity and various characteristics of the child's bedroom, as reported in the questionnaire, are shown in table 1. Multiple regression modelling, with a stepdown approach, was used to determine the extent to which adjusted temperature and relative humidity could be predicted by questionnaire information. $\mathbf{A}$ model including day heat, night heat, open window, and condensation on windows accounted for $14.6 \%$ of the 
Table 1 Mean adjusted temperature and relative humidity in child's bedroom by occupancy, heating, ventilation, dampness and mould growth.

\begin{tabular}{|c|c|c|c|c|c|c|}
\hline & & $\begin{array}{l}\text { Number } \\
\text { of homes }\end{array}$ & $\begin{array}{l}\text { Adjusted } \\
\text { temp }\left({ }^{\circ} \mathrm{C}\right)\end{array}$ & $\mathrm{t}$ & $\begin{array}{l}\text { Adjusted } \\
R H(\%)\end{array}$ & $t$ \\
\hline Child shares bedroom & $\begin{array}{l}\text { No } \\
\text { Yes }\end{array}$ & $\begin{array}{l}128 \\
189\end{array}$ & $\begin{array}{l}18 \cdot 1 \\
17 \cdot 7\end{array}$ & -1.5 & $\begin{array}{l}51 \cdot 5 \\
53 \cdot 8\end{array}$ & 1.0 \\
\hline $\begin{array}{l}\text { Heat in bedroom } \\
\text { during winter } \\
\text { months }\end{array}$ & $\begin{array}{l}\text { None } \\
\text { Night only } \\
\text { Day only } \\
\text { Day \& night }\end{array}$ & $\begin{array}{r}113 \\
104 \\
\\
41 \\
59\end{array}$ & $\left.\begin{array}{l}17 \cdot 1 \\
17.8\end{array}\right\}$ & 3.8 & $\left.\begin{array}{l}53.4 \\
54.5\end{array}\right\}$ & $-2 \cdot 6$ \\
\hline $\begin{array}{c}\text { Window usually } \\
\text { open at night }\end{array}$ & $\begin{array}{l}\text { No } \\
\text { Yes }\end{array}$ & $\begin{array}{r}277 \\
40\end{array}$ & $\begin{array}{l}17 \cdot 9 \\
17 \cdot 7\end{array}$ & -0.7 & $\begin{array}{l}53 \cdot 0 \\
52 \cdot 1\end{array}$ & -0.8 \\
\hline $\begin{array}{l}\text { Condensation } \\
\text { forms on window }\end{array}$ & $\begin{array}{l}\text { No } \\
\text { Yes }\end{array}$ & $\begin{array}{r}90 \\
227\end{array}$ & $\begin{array}{l}18 \cdot 5 \\
17 \cdot 5\end{array}$ & $-4 \cdot 6$ & $\begin{array}{l}51 \cdot 5 \\
53 \cdot 5\end{array}$ & $2 \cdot 5$ \\
\hline $\begin{array}{l}\text { Condensation or } \\
\text { damp on walls }\end{array}$ & $\begin{array}{l}\text { No } \\
\text { Yes }\end{array}$ & $\begin{array}{r}270 \\
37\end{array}$ & $\begin{array}{l}17 \cdot 9 \\
17 \cdot 2\end{array}$ & $-2 \cdot 4$ & $\begin{array}{l}54 \cdot 3 \\
56 \cdot 7\end{array}$ & 3.8 \\
\hline $\begin{array}{l}\text { Patches of } \\
\text { mould or fungus }\end{array}$ & $\begin{array}{l}\text { No } \\
\text { Yes }\end{array}$ & $\begin{array}{r}289 \\
28\end{array}$ & $\begin{array}{l}17 \cdot 9 \\
17 \cdot 4\end{array}$ & $-1 \cdot 2$ & $\begin{array}{l}52 \cdot 5 \\
56 \cdot 7\end{array}$ & $3 \cdot 2$ \\
\hline
\end{tabular}

Student's $t$ tests for difference between means have $315 \mathrm{df}$.

variance in adjusted mean weekly temperature. heat, and dampness on walls. However, together these Inclusion of tenure as a further predictor improved the model slightly, then explaining $16 \cdot 4 \%$ of the variance. For adjusted relative humidity, the significant predictors were: children sharing the room, daytime accounted for only $10 \%$ of the variance in adjusted relative humidity. By comparison, moisture content as $2 \frac{2}{9}$ measured in the wood block survey accounted for $ᄋ \frac{0}{3}$ $24 \%$ of the variance. Although the 37 bedrooms

Table 2 Prevalence (\%) of respiratory symptoms by dampness and mould in the home

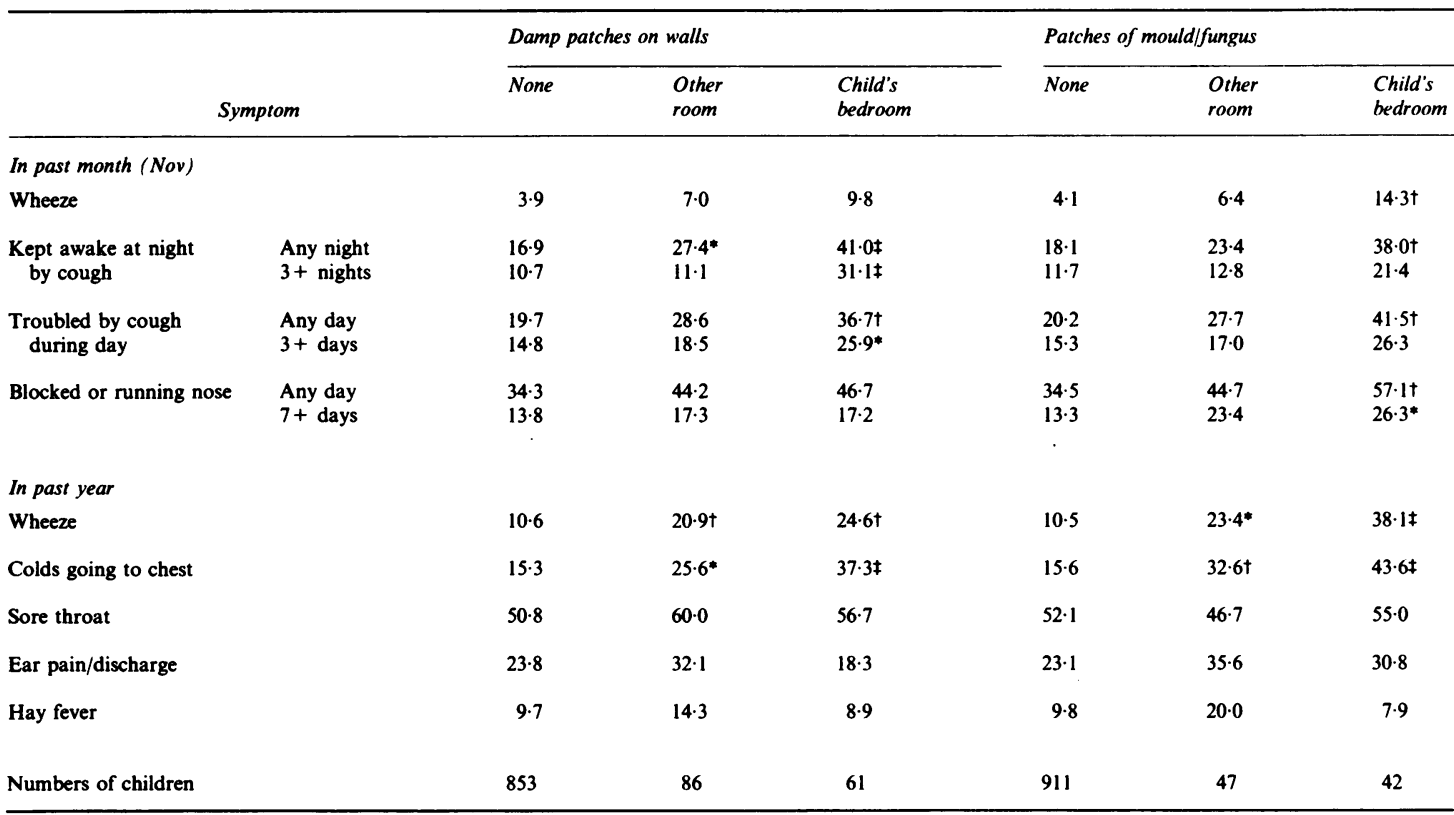

Significance tests for difference from prevalence in unaffected homes:

$* \mathrm{p}<0.05 ; \quad+\mathrm{p}<0.01 ; \quad \neq \mathrm{p}<0.001$ 
reported to be damp were, on average, more humid, only 17 were in the top quartile of adjusted relative humidity; nine were below the median of this distribution.

The questionnaire data revealed a strong association between cough, wheeze and chest colds experienced by the child over the past year and reports of dampness or mould growth in the home (table 2). In contrast, no association was found between damp or mould and symptoms attributable to the upper respiratory tract, with the exception of nasal discharge. The analysis of these relationships and their association with other features of the home environment will be reported in greater detail elsewhere. In this paper, we concentrate upon the relationships between objective measurements of bedroom conditions and respiratory symptoms, ventilatory function and bronchial lability to exercise.

Table 3 shows the prevalence of each symptom by quintiles of relative humidity, as assessed semiquantitatively by wood block moisture content. Although this was a relatively imprecise surrogate measure of bedroom conditions, it permitted the simultaneous ranking of the humidity in a large number of homes, free from the assumptions implicit in the adjustment of thermohygrograph recordings. No symptom had a significant positive relationship with moisture content, nor was there clear evidence of an increase in prevalence in the top quintile. For hayfever, there was an inverse association which reached significance at the $5 \%$ level, but in view of the multiple comparisons being made, this significance test should be interpreted with caution.

Table 4 expresses the relationship between the same symptoms and the thermohygrograph recordings, in terms of the mean adjusted temperature and relative humidity values for the bedrooms of children with and without each symptom. The differences in bedroom conditions between symptomatic and asymptomatic groups were small and, in every case failed to reach conventional levels of statistical significance. The comparison of mean values might be misleading if the true relationship between home conditions and symptoms were curved rather than linear. Logistic

Table 3 Prevalence (\%) of symptoms by quintiles of bedroom relative humidity (simultaneous estimation from the moisture content of 778 wood blocks)

\begin{tabular}{|c|c|c|c|c|c|c|c|}
\hline Symptoms & $\begin{array}{l}\text { Quint } \\
\text { (low) } \\
l\end{array}$ & $\begin{array}{l}\text { ire con } \\
2\end{array}$ & 3 & 4 & 5 & $\begin{array}{l}\chi^{2} \text { for } \\
5 \times 1-4 \\
(1 d f)\end{array}$ & $\begin{array}{l}\chi^{2} \\
\text { for trend } \\
(1 \text { df })\end{array}$ \\
\hline \multicolumn{8}{|l|}{ In past month (Nov) } \\
\hline $\begin{array}{l}\text { Night cough (any) } \\
\text { Day cough (any) } \\
\text { Running nose (any) }\end{array}$ & $\begin{array}{l}18 \cdot 8 \\
21 \cdot 5 \\
37 \cdot 5\end{array}$ & $\begin{array}{l}21 \cdot 5 \\
26 \cdot 4 \\
38 \cdot 2\end{array}$ & $\begin{array}{l}14 \cdot 5 \\
18 \cdot 1 \\
33 \cdot 3\end{array}$ & $\begin{array}{l}16 \cdot 9 \\
21 \cdot 6 \\
38 \cdot 6\end{array}$ & $\begin{array}{l}24 \cdot 1 \\
23 \cdot 7 \\
33 \cdot 3\end{array}$ & $\begin{array}{l}2 \cdot 6 \\
0.2 \\
0.6\end{array}$ & $\begin{array}{l}0.4 \\
0.0 \\
0.5\end{array}$ \\
\hline \multicolumn{8}{|l|}{ In past year } \\
\hline $\begin{array}{l}\text { Wheeze } \\
\text { Colds to the chest } \\
\text { Sore throat } \\
\text { Ear pain/discharge } \\
\text { Hay fever }\end{array}$ & $\begin{array}{l}10 \cdot 6 \\
15 \cdot 7 \\
53 \cdot 8 \\
23 \cdot 7 \\
13 \cdot 4\end{array}$ & $\begin{array}{l}13 \cdot 8 \\
20 \cdot 1 \\
47 \cdot 2 \\
28 \cdot 1 \\
15 \cdot 2\end{array}$ & $\begin{array}{r}12 \cdot 3 \\
12 \cdot 4 \\
54 \cdot 0 \\
24 \cdot 3 \\
6 \cdot 0\end{array}$ & $\begin{array}{r}16 \cdot 2 \\
14 \cdot 1 \\
52 \cdot 0 \\
22 \cdot 4 \\
9 \cdot 5\end{array}$ & $\begin{array}{r}8.9 \\
20 \cdot 0 \\
55 \cdot 2 \\
20 \cdot 9 \\
8 \cdot 0\end{array}$ & $\begin{array}{l}1.8 \\
1.5 \\
0.4 \\
0.7 \\
0.7\end{array}$ & $\begin{array}{l}0 \cdot 0 \\
0 \cdot 1 \\
0 \cdot 3 \\
0.9 \\
4 \cdot 3\end{array}$ \\
\hline
\end{tabular}

Table 4 Mean adjusted temperature and relative humidity in bedrooms of children with and without respiratory symptoms

\begin{tabular}{|c|c|c|c|c|c|c|}
\hline \multirow[b]{2}{*}{ Symptom } & \multicolumn{3}{|c|}{ Mean adjusted temp $\left({ }^{\circ} \mathrm{C}\right)$} & \multicolumn{3}{|c|}{ Mean adjusted relative humidity (\%) } \\
\hline & $\begin{array}{l}\text { No } \\
\text { symptoms }\end{array}$ & $\begin{array}{l}\text { With } \\
\text { symptoms }\end{array}$ & $t$ & $\begin{array}{l}\text { No } \\
\text { symptoms }\end{array}$ & $\begin{array}{l}\text { With } \\
\text { symptoms }\end{array}$ & $t$ \\
\hline \multicolumn{7}{|l|}{ In past month (Nov) } \\
\hline $\begin{array}{l}\text { Night cough (any) } \\
\text { Day cough (any) } \\
\text { Running nose (any) }\end{array}$ & $\begin{array}{l}17 \cdot 94 \\
17 \cdot 91 \\
17 \cdot 72\end{array}$ & $\begin{array}{l}17 \cdot 51 \\
17 \cdot 55 \\
18 \cdot 02\end{array}$ & $\begin{array}{r}-1.9 \\
-1.5 \\
1.4\end{array}$ & $\begin{array}{l}52 \cdot 74 \\
52 \cdot 65 \\
53 \cdot 30\end{array}$ & $\begin{array}{l}53 \cdot 34 \\
53 \cdot 65 \\
52 \cdot 11\end{array}$ & $\begin{array}{r}0.7 \\
1.2 \\
-1.5\end{array}$ \\
\hline \multicolumn{7}{|l|}{ In past year } \\
\hline $\begin{array}{l}\text { Wheeze } \\
\text { Colds to the chest } \\
\text { Sore throat } \\
\text { Ear pain/discharge } \\
\text { Hay fever }\end{array}$ & $\begin{array}{l}17 \cdot 88 \\
17 \cdot 88 \\
17 \cdot 81 \\
17 \cdot 80 \\
17 \cdot 78\end{array}$ & $\begin{array}{l}17 \cdot 51 \\
17 \cdot 65 \\
17 \cdot 85 \\
17 \cdot 89 \\
18 \cdot 32\end{array}$ & $\begin{array}{r}-1.3 \\
-0.9 \\
0.2 \\
0.4 \\
1.4\end{array}$ & $\begin{array}{l}52 \cdot 73 \\
53 \cdot 00 \\
52 \cdot 64 \\
52 \cdot 67 \\
52.99\end{array}$ & $\begin{array}{l}53.87 \\
52 \cdot 53 \\
53.09 \\
53.51 \\
51.69\end{array}$ & $\begin{array}{r}1.1 \\
-0.5 \\
0.6 \\
1.0 \\
-0.9\end{array}$ \\
\hline
\end{tabular}

Student's $t$ tests for differences between means have $315 \mathrm{df}$. 
regression modelling was therefore performed to investigate departures from linearity. For no symptom did the inclusion of quadratic terms for temperature or relative humidity substantially improve the model.

The relationship between adjusted temperature and relative humidity and height adjusted $\mathrm{FEV}_{1}$ before exercise was assessed. Treating each variable as a continuous measurement, small and insignificant correlations were found with temperature $(r=-0.02)$, and relative humidity $(r=-0.06)$. A range of other ventilatory function indices, including FEV $_{0.5}$, FEV $_{0.5} /$ FVC, FEV $_{1} /$ FVC, FEF $_{25-75 \%}$ and FEF $_{75-85 \%}$ and PEFR, were studied in a similar manner. These measures proved less repeatable than $F_{1} V_{1}$ in our study population, and their relationships with temperature and humidity were similarly tenuous.

A satisfactory exercise test was completed by 314 of the 317 children whose homes were monitored. The remaining three children were tested on treatment (one on oral theophyllines, two on inhaled steroids). Exercise induced bronchial lability was analysed both as a dichotomous variable and as a continuous outcome. When a cut off point of 0.8 was used to define post exercise bronchospasm, the prevalence of abnormality was $5.4 \%(17 / 314)$. Mean adjusted temperature was $17 \cdot 78^{\circ} \mathrm{C}$ among the 17 children with bronchospasm, and $17.82^{\circ} \mathrm{C}$ among the remainder $(\mathrm{t}=-0.03,313 \mathrm{df})$. Corresponding mean adjusted relative humidity levels were $53.2 \%$ and $52.8 \%$ $(t=0 \cdot 19,313 \mathrm{df})$. The correlations between lability (as a continuous variable) and bedroom conditions were similarly weak; $r=-0.02$ for temperature, and $r=-0.09$ for relative humidity. The mean adjusted temperature and relative humidity in the bedrooms of the three excluded children were $17.67^{\circ} \mathrm{C}$ and $47.3 \%$, respectively.

\section{Discussion}

Those studies that have specifically addressed the relationship between respiratory disease and dampness in the home generally agree with our finding of an association between reported dampness and cough and wheeze in children. ${ }^{514} 15$ The strength and specificity of the relationships that we demonstrate in this sample of the general population warrant attention. Associations with upper respiratory symptoms were generally weak, but the prevalence ratio for wheeze was of the same order as that found in associations with hayfever or eczema in this age group, and much greater than previously described for any other environmental factor. ${ }^{22} 23$

On the other hand, if dampness in widely held to be a cause of ill health by the general public, associations based entirely on questionnaire information must be considered prone to reporting bias. This could operate in two ways; parents of symptomatic children may become more aware of adverse home conditions, or parents who are already aware of dampness in their home might more readily report symptoms in their children. ${ }^{15}$

Martin et al ${ }^{5}$ validated reports of dampness using independent assessments by environmental health officers, and found a high degree of concordance. Their approach is attractive in that it considered dampness in its entirety, using criteria which decide priority for rehousing. However, such a global assessment may be less useful where the aim is to set quantitative building standards. ${ }^{24}$ It is unclear to what extent observers might be influenced by comments or guidance from the householders, nor how their assessments varied with season. The number of children studied was small and without information about their age distribution, it is difficult to interpret the reported association between dampness and respiratory symptoms, which was only significant when a combination of both upper and lower respiratory symptoms was considered.

Melia et al $^{14}$ used thermohygrographs similar to ours, although they did not control for climatico variation. The humidity levels reported were higher than we recorded in Edinburgh homes, but this may be due to exceptionally low levels of outdoor vapour pressure during the winter months of our study. They? found a significant excess of lower respiratory symptoms in the children with the most humid bedrooms, but these data relate to only $44 \%$ of their target sample. It is possible that families who were aware of both dampness and respiratory problems were more likely to have responded to their survey, and because the information about symptoms was collected after the thermohygrograph recordings, no assessment of such bias was possible.

In the present study, an encouraging response was achieved from a sample of the general population, and non-response bias appeared to be minimal. The choice of objective criteria for both disease and outcome allowed us to address both types of reporting bias mentioned above. The interpretation of our negative findings rests upon the validity of the objective indices chosen and the power of the study to detect true effects of a magnitude which would be considered of public health importance. Related to both these issues is the effect of random errors in the measurements which will attenuate real associations and reduce the power of significance tests. An additional consideration may be the effect of chronic respiratory disease in the child upon parental decisions about heating and ventilation in the child's bedroom. In this regard, it is relevant to note that no excess of symptoms was observed in the warmest, driest bedrooms. 
Wheeze was one of the less prevalent symptoms, but the one which might be expected to show the closest association with humidity. With a true overall prevalence of $12 \%$ for wheeze in the past year, a difference between a prevalence of $6 \%$ in the lowest tertile of temperature or relative humidity and $18 \%$ in the top tertile might be of considerable research and policy interest. The study of 317 homes had a power of $77 \%$ to detect such a trend as significant at the $5 \%$ level, and correspondingly greater power for more prevalent symptoms. Furthermore, many of the observed differences in temperature and relative humidity between symptomatic and asymptomatic groups were close to zero, implying that a very much larger study would have been required to demonstrate them as statistically significant. The public health importance of such minimal effects must be questioned.

On biological grounds, the most plausible causal links between dampness and respiratory disease implicate functional abnormalities of the airways, resulting from increased exposure to airborne allergens or intercurrent infections. Assessment of bronchial lability by exercise proved highly acceptable to the children, and, being a common physiological stimulus, carried intrinsic validity. Although the prevalence of unequivocal abnormality was rather low, the analysis of lability as a continuous variable permitted a more powerful test of environmental effects. It is possible that a pharmacological challenge $^{25}$ would provide a more sensitive test of airways reactivity which might correlate more strongly with housing conditions. In view of the negative relationships between bedroom temperature and humidity and symptoms attributable to asthma, we consider this unlikely.

Ambient relative humidity was readily monitored in an objective and standardised manner, but limited equipment and manpower inevitably resulted in recordings spread over a number of weeks. This is the first study to attempt an adjustment for climatic variation, but, strictly, our procedure may not be generalisable beyond the five homes from which it was derived. The additional analyses using a simultaneous semiquantitative estimate of relative humidity goes some way towards meeting such reservations.

A more serious limitation of our findings is that airborne humidity may be a poor indicator of biologically relevant exposure. House dust mites thrive in homes considered to be damp, ${ }^{26}$ but it is reasonable to suppose that this is because the relative humidity in soft furnishings is influenced by the ambient humidity of the room. ${ }^{6}$ We found that reported dampness was not a good predictor of humidity ranking, probably because the formation of patches of condensation on walls depends upon the temperature of the wall (reflecting the efficiency of insulation) as well as the humidity of the air in the room. The relative humidity of the cold or moist indoor microenvironments suitable for mould growth may be poorly represented by measurements of the air in one room of the house. In a case-control study of adult asthma, visible mould in the home was reported more commonly by cases, ${ }^{27}$ and in the questionnaire survey that we report here, associations with reported mould were generally stronger than with dampness. The investigation of reporting bias in this context is the subject of ongoing studies of airborne fungal spores in selected homes from the same population sample.

The fieldwork was completed while DPS held a Wellcome Research Training Fellowship, and was supported by funds from the Asthma Research Council. Our thanks are due to Ms B Somerville and Ms A Calderwood for assistance with the thermohygrograph survey, and to Ms P Ross for assistance with the medical examinations. We are indebted to the Metereological Office for providing daily temperature and relative humidity recordings from Turnhouse Airport.

Correspondence and reprints to: Dr D P Strachan, Lecturer in Epidemiology, Department of Epidemiology, London School of Hygiene and Tropical Medicine, Keppel St, London WC1E 7HT.

\section{References}

${ }^{1}$ Sanders CH, Cornish JP. Dampness: one week's complaints in five local authorities in England and Wales. London: HMSO, 1982.

${ }^{2}$ Scottish Development Department Building Directorate. Condensation in housing. A report on local authority returns, survey results and remedial measures. Edinburgh: Scottish Office, 1984.

${ }^{3}$ Building Research Establishment. The English House Condition Survey. London: HMSO, 1985.

${ }^{4}$ McCarthy P, Byrne D, Harrison S, Keithly J. Respiratory conditions: effect of housing and other factors. $J$ Epidemiol Community Health 1985; 39: 15-9.

${ }^{5}$ Martin CJ, Platt SD, Hunt SM. Housing conditions and ill-health. Br Med J 1987; 294: 1125-7.

${ }^{6}$ Blythe ME. Some aspects of the ecological study of the house dust mites. Br J Dis Chest 1976; 70: 3-31.

${ }^{7}$ Block SS. Humidity requirements for mould growth. Applied Microbiol 1953; 1: 287-93.

${ }^{8}$ Horn MEC, Reed SE, Taylor P. Role of viruses and bacteria in acute wheezy bronchitis in childhood: a study of sputum. Arch Dis Child 1979; 54: 587-92.

${ }^{9}$ Carlsen KH, Orstank I, Leegaard J, Hoeg H. Respiratory virus infections and aeroallergens in acute bronchial asthma. Arch Dis Child 1984; 59: 310-5.

${ }^{10}$ Kingdom KH. Relative humidity and air-borne infections. Am Rev Respir Dis 1960; 81: 504-12. 
${ }^{11}$ Buckland FE, Tyrell DAJ. Loss of infectivity on drying various viruses. Nature 1962; 195: 1063-4.

12 Hope-Simpson RE. Common upper respiratory diseases. $J$ $R$ Soc Health 1958; 78: 593-9.

${ }^{13}$ Burr ML, St. Leger AS, Yarness JWG. Wheezing, dampness and coal fires. Community Med 1981; 3: 205-9.

${ }^{14}$ Melia RJW, Florey CDV, Morris RW, et al. Childhood respiratory illness and the home environment. II: Association between respiratory illnesses and nitrogen dioxide, temperature and relative humidity. Int $J$ Epidemiol 1982; 11: 164-9.

${ }^{15}$ Strachan DP, Elton RA. Relationship between respiratory morbidity in children and the home environment. Family Practice 1986; 3: 137-42.

16 Speight ANP, Lee DA, Hay EN. Underdiagnosis and undertreatment of asthma in childhood. Br Med J 1983; 286: 1253-6.

17 ATS Statement. Snowbird workshop on standardization of spirometry. Am Rev Respir Dis 1979; 119: 831-8.

18 Silverman M, Anderson SD. Standardisation of exercise tests in asthmatic children. Arch Dis Child 1972; 47: 882-9.

${ }^{19}$ British Standards Institution. Definitions, formulae and constants relating to the humidity of the air. BS 1339: 1965. London: British Standards Institution, 1965.
${ }^{20}$ SPSS-X User's Guide. New York: McGraw-Hill, 1986.

${ }^{21}$ Baker RJ, Nelder JA. The GLIM system manual (release 3). Oxford: Numerical Algorithms Group, 1978.

${ }^{22}$ Anderson HR, Bland JM, Patel S, Peckham C. The natural history of asthma in childhood. $J$ Epidemiol Community Health 1986; 40: 121-9.

${ }^{23}$ Butler NR, Golding J. From birth to five. A study of the health and behaviour of Britain's five-year-olds. (Chapter 11: Wheezing and asthma) Oxford: Pergamon Press, 1986: 158-70.

${ }^{24}$ Mant DC, Muir Gray JA. Building regulation and health. Watford: Building Research Establishment, 1986.

${ }^{25}$ Lee DA, Winslow NR, Speight ANP, Hey EN. Prevalence and spectrum of asthma in childhood. $\mathrm{Br}$ Med $J$ 1983; 286: 1256-8.

${ }^{26}$ Burr ML, Dean BV, Merrett TG, et al. Effects of anti-mite measures on children with mite-sensitive asthma: a controlled trial. Thorax 1980; 35: 506-12.

${ }^{27}$ Burr ML, Mullins J, Merrett TG, Stott NCH. Asthma and indoor mould exposure. Thorax 1985; 40: 688.

Accepted for publication September 1988 